Keywords: aromatase inhibitor; withdrawal response; breast cancer; hormone-receptor-positive tumours; metastatic; endocrine therapy

\title{
Drug withdrawal in women with progressive metastatic breast cancer while on aromatase inhibitor therapy
}

\author{
Y Chavarri-Guerra ${ }^{1}, \mathrm{M}$ J Higgins ${ }^{2}$, J Szymonifka ${ }^{2}$, T Cigler $^{3}$, P Liedke ${ }^{2}$, A Partridge $^{4}$, J Ligibel ${ }^{4}$, S E Come ${ }^{5}$, \\ D Finkelstein ${ }^{2}$, P D Ryan ${ }^{6}$ and P E Goss ${ }^{\star}, 2$ \\ ${ }^{1}$ Instituto Nacional de Ciencias Médicas y Nutrición, Salvador Zubirán, Mexico City, Mexico; ${ }^{2}$ Massachusetts General Hospital \\ Cancer Center, Boston, MA, USA; ${ }^{3}$ Weill Cornell Medical College, New York, NY, USA; ${ }^{4}$ Dana-Farber Cancer Institute, Boston, MA, \\ USA; ${ }^{5}$ Beth Israel Deaconess Medical Center, Boston, MA, USA and ${ }^{6}$ Fox Chase Cancer Center, Philadelphia, PA, USA
}

Background: Acquiring resistance to endocrine therapy is common in metastatic hormone-receptor-positive breast cancer (MBC). These patients most often transition either to next-line endocrine therapy or to systemic chemotherapy. However, withdrawal of endocrine therapy and observation as is selectively practiced in prostate cancer is another potential strategy for breast cancer patients.

Methods: A prospective, single-arm phase II trial of aromatase inhibitor (AI) withdrawal was performed in women with MBC, who had disease progression on Al therapy. The primary objective was to estimate the clinical benefit rate (defined as complete or partial response, or stable disease for at least 24 weeks, by RECIST criteria). Participants were monitored clinically and radiographically off all therapy at 8,16 and 24 weeks after treatment and every 12 weeks thereafter until disease progression.

Results: Twenty-four patients (of 40 intended) were enrolled when the study was closed due to slow accrual. Clinical benefit rate overall was $46 \%$ (95\% Cl $26 \%$ to $67 \%$ ). Median progression-free survival from time of Al withdrawal was 4 months. Two patients have remained progression free, off all treatment, for over 60 months.

Conclusions: Despite suboptimal patient accrual, our results suggest that selected patients with metastatic breast cancer progressing on $\mathrm{Al}$ therapy can experience disease stabilisation and a period of observation after Al withdrawal. A randomised phase II trial is planned.

The development of resistance to standard endocrine therapy is a common problem for patients with oestrogen receptor-positive $(\mathrm{ER}+)$ metastatic breast cancer. Third-generation aromatase inhibitors (AIs) have shown superiority over tamoxifen in the treatment of both early and metastatic ER + breast cancer (MBC) in postmenopausal women, and are now the most commonly used first-line endocrine therapy (Bonneterre et al, 2000; Nabholtz et al, 2000; Mouridsen et al, 2001; Milla-Santos et al, 2003; Paridaens et al, 2008). However, despite persistent expression of the ER in a majority of recurring tumours, even when an initial response is seen to standard endocrine therapies all tumours eventually develop resistance to endocrine therapy and the disease progresses (Johnston, 2010). Upon progression, patients are usually treated with second-line endocrine therapy or cytotoxic chemotherapy, which usually cause significant toxicities with response rates of only 10-20\% (Chia et al, 2008; Di Leo et al, 2011).

Tumour response after withdrawal of endocrine therapy was first described following disease progression on tamoxifen treatment, and several subsequent case reports and small case series have reported similar responses to withdrawal of AIs

*Correspondence: Dr PE Goss; E-mail: pgoss@partners.org

Results were presented in abstract form at the American Society of Clinical Oncology Annual Meeting in Chicago, June 2011.

Received 9 April 2014; revised 29 July 2014; accepted 18 August 2014; published online 18 September 2014

(c) 2014 Cancer Research UK. All rights reserved 0007-0920/14 
(Legault-Poisson et al, 1979; Belani et al, 1989; Bhide and Rea, 2004; Cigler and Goss, 2006; Agrawal et al, 2011; Lambertini et al, 2011; Table 1).

Both in vitro and in vivo, breast cancer cells exposed to longterm oestrogen deprivation, comparable to that induced by aromatase inhibition in patients, become increasingly sensitive to growth stimulation by low levels of oestrogen and may have growth arrested in response to oestrogen concentrations that initially caused growth progression (Masamura et al, 1995; Shim et al, 2000; Song et al, 2001; Osipo et al, 2005). Thus, extremely low-oestrogen resultant upon 'anti-oestrogen' therapy such as AI therapy may sensitise the tumour cells to the low but normal levels of oestrogen found in postmenopausal women after AI withdrawal. Based on this hypothesis and the preclinical data related to extreme sensitivity to oestrogen after disease progression on AI therapy and because of the short half-lives of AIs (Guerrieri-Gonzaga et al, 2001; Buzdar et al, 2002), and supported by the abrupt resolution of AI-induced vasomotor symptoms, we conducted a prospective phase II clinical trial of observation after AI withdrawal for MBC.

\section{MATERIALS AND METHODS}

Eligibility. Eligible patients were postmenopausal women aged $\geqslant 35$ years who had a diagnosis of histologically or cytologically confirmed hormone-receptor-positive (ER + and/or progesteronereceptor-positive $(\mathrm{PR}+))$ breast cancer with radiographically documented progressive or recurrent unresectable local-regional or metastatic disease. Prior treatment must have included AI monotherapy at the time of documented disease progression and this AI therapy was required to be discontinued at the time of study entry or $<2$ weeks prior to study entry. Patients who received $\mathrm{AI}$ therapy for $\mathrm{MBC}$ at the time of progression had to have had a prior radiographically documented response to AI therapy or to have been on therapy for at least 6 months. All patients were defined as postmenopausal at the time of enrolment by the following criteria: if $>50$ years, no menses within the past 12 months; or if $<50$ years, no menses within the past 12 months and FSH within postmenopausal range; or bilateral oophorectomies. All patients had to have been considered postmenopausal and eligible for prior AI therapy by their treating physician. Patients were eligible if they had measurable or non-measurable (but evaluable: defined as non-target lesions) disease according to modified Response Evaluation Criteria in Solid Tumors (RECIST 1.0; Therasse et al, 2000); patients with bone-only disease were also eligible; with Eastern Cooperative Oncology Group (ECOG) performance status of $0-2$. Patients were excluded if they had life-threatening metastatic disease, had extensive hepatic involvement, had any past or present brain or leptomeningeal involvement, or symptomatic pulmonary lymphangitic spread, were highly symptomatic from their breast cancer; or if, in the opinion of their treating physician, they required urgent palliative chemotherapy. Prior or planned radiation therapy to a single site of evaluable disease in the event that the lesion was the only site of evaluable disease was also an exclusion criterion. Any number of prior endocrine or chemotherapy treatments for treatment of advanced breast cancer was allowed. However, concurrent alternative systemic anticancer therapy was not permitted. Concurrent bisphosphonate therapy was allowed if the therapy was initiated prior to enrolment.

Study design. The study was a single-arm phase II study of women who developed recurrent or progressive metastatic breast cancer while being treated with an AI. Within 2 weeks prior to study entry, all participants had to discontinue AI therapy and were subsequently actively followed off all therapy until disease progression or consent withdrawal. The primary end point was clinical benefit rate (CBR), which was defined as the proportion of patients with a complete response (CR), partial response (PR) or stable disease for a minimum of 24 weeks from the baseline point of AI withdrawal. The secondary end points were: progression-free survival (PFS) (defined as the interval between the date of AI discontinuation and the date of disease progression) and objective response rate (CR or $\mathrm{PR}$ ) in patients who had measurable disease as defined by RECIST 1.0 at baseline.

The protocol was approved by the Dana-Farber/Harvard Cancer Center Institutional Review Board and written informed consent was obtained from all patients.

Study considerations. At the time of study entry, a complete medical history, physical examination, computed tomography scan of the chest, abdomen and pelvis, bone scans and blood work were obtained.

Once enrolled, participants were observed off all therapy until disease progression. Restaging studies including physical examination, blood chemistry, tumour marker (if available at participating institutions) and complete radiographic assessments were performed at 8, 16 and 24 weeks after AI discontinuation and every 12 weeks thereafter (Figure 1).

Statistical analysis. The trial planned to enrol 40 patients in two stages in order to have a $90 \%$ power to detect a true CBR of $20 \%$ using a Simon's two-stage design. In the first stage, 13 patients were to be accrued. If there was at least one patient with clinical benefit, an additional 27 patients were to be accrued. A 5\% 'lost to follow-up' rate at 6 months was assumed.

The primary end point analysis consisted of the point estimate for the CBR and an exact binomial 95\% confidence interval (CI) was reported. Patients lost to follow-up prior to 6 months, who were last known to be alive and progression free, were excluded from the CBR analysis. Estimates of PFS with their associated 95\% CIs were calculated using the Kaplan-Meier product-limit method and Greenwood's formula. All enrolled patients were included in the PFS analysis, regardless of length of follow-up.

\section{RESULTS}

Patients. A total of 24 patients were enrolled from three centres (Massachusetts General Hospital, Beth Israel Deaconess Medical

Table 1. Retrospective experience with Al withdrawal

\begin{tabular}{|c|c|c|c|c|c|}
\hline Author, year & $N$ & Drug & Site & $\begin{array}{l}\text { Clinical } \\
\text { benefit }\end{array}$ & $\begin{array}{l}\text { Duration } \\
\text { in months }\end{array}$ \\
\hline Agrawal et al, 2011 & 17 & $\begin{array}{l}10 \text { Tamoxifen, } 5 \mathrm{Al} \text { ( } 4 \text { exemestane and } 1 \text { letrozole), } \\
1 \text { megestrol and } 1 \text { fulvestrant }\end{array}$ & Bone, pleura, lung, liver and lymph nodes & $58.8 \%$ & $9+$ \\
\hline Lambertini et al, 2011 & 1 & Letrozole & Breast and axillary nodes & $\mathrm{CR}$ & $10+$ \\
\hline Cigler and Goss, 2006 & 1 & Goserelin + letrozole & Liver and bone & PR & $14+$ \\
\hline Bhide and Rea, 2004 & 1 & Exemestane & Supraclavicular mass & PR & $12+$ \\
\hline
\end{tabular}




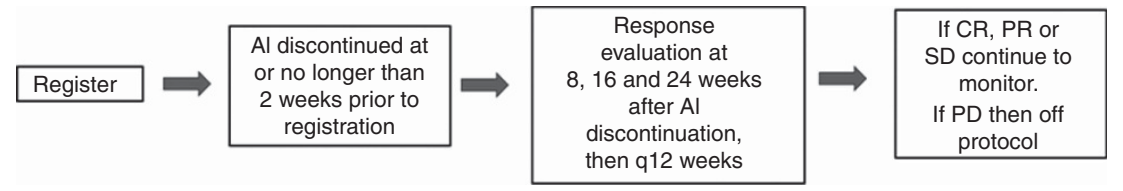

Figure 1. Participants were observed off all therapy and evaluated for tumour response by examination, blood chemistry, tumour marker (if available at participating institutions) and complete radiographic assessment at 8,16 and 24 weeks after Al discontinuation and every 12 weeks thereafter.

Center and Dana-Farber Cancer Institute) between October 2006 and December 2009, at which time the study was closed by the Dana-Farber Scientific Review Committee due to slow accrual. The baseline demographic and clinical characteristics of the patients are summarised in Tables 2 and 3. The median age was 63 years and the most common metastatic disease sites at baseline were bone in $21(88 \%)$, lung in $9(38 \%)$ and liver in $5(21 \%)$ of the patients. Seven patients $(29 \%)$ had bone-only disease. All patients received at least one metastatic or adjuvant prior endocrine therapy (metastatic setting 23 of 24 patients (96\%), adjuvant setting 18 of 22 patients $(82 \%)$ ) with a median of 1 (range $1-4)$ prior endocrine therapies in the metastatic setting.

Efficacy. At a median follow-up of 33.9 months, 22 subjects were evaluable for response. The remaining two patients had $<24$ weeks of follow-up, but were still progression free as of their date of last contact. The proportion of patients that achieved a CBR at 24 weeks was $46 \%$ (exact binomial 95\% CI 26\% to 67\%), including 7 of 13 patients accrued for the first stage of the study. No CRs or PRs were observed. The median PFS of all patients was 4.47 months (95\% CI 1.7 months to 17.2 months; Figure 2). Two patients have remained progression free over 60 months from the time of AI withdrawal on protocol, off all therapy. There were 14 reported deaths, occurred between 13 and 73.4 months following AI withdrawal, all of them related to disease progression. The median overall survival of all patients was 38.8 months (Figure 3).

\section{DISCUSSION}

This first prospective trial designed to determine the withdrawal response rate after AI cessation demonstrated a CBR at 6 months of $46 \%$ ( $n=10$ of 22 ). These results are encouraging and consistent with, and supported by, preclinical data in cell lines and xenograft models of oestrogen deprivation on disease progression (Masamura et al, 1995; Shim et al, 2000; Song et al, 2001; Osipo et al, 2005). The data show that cells deprived of oestrogen are able to adapt to anti-oestrogen therapy and eventually may become growth-stimulated rather than inhibited. In ER + cell lines subjected to long-term oestrogen deprivation, the addition of low-dose oestrogen therapy paradoxically induces apoptosis, and a complete reversal of resistance to endocrine therapy has been shown (Masamura et al, 1995; Osipo et al, 2005).

In the clinical setting, Howell et al (1992), found in women with MBC that after prior lack of response to tamoxifen (19\%) or after adjuvant tamoxifen followed by disease progression, $14 \%$ of patients experience stable disease (or disease response) when tamoxifen was stopped and the patients were observed. Although, it appears paradoxical that cessation of 'anti-oestrogen' therapy and subsequent exposure of tumour cells once again to normal circulating levels of oestrogens should induce disease regression, preclinical models have provided supportive evidence that this happens on occasion. Disease responses have also been seen in this setting of acquired disease resistance when therapeutic
Table 2. Baseline patient demographics and clinical characteristics

Characteristics n $(N=24)$ Percentage

Age, years

\begin{tabular}{|c|c}
\hline Median & 63
\end{tabular}

\begin{tabular}{l|r} 
Range & $43-76$
\end{tabular}

ECOG Performance status

\begin{tabular}{|l|r|r|}
\hline 0 & 21 & 88 \\
1 & 3 & 13 \\
\hline Race & 23 & 96 \\
\hline White & 1 & 4 \\
Black
\end{tabular}

Time since initial diagnosis

\begin{tabular}{|c|c} 
Median (years) & 10
\end{tabular}

Range $1-23$

\begin{tabular}{|l|l|l|}
\hline Stage at initial diagnosis \\
\hline I & 3 & 13 \\
II & 9 & 38 \\
III & 3 & 13 \\
IV & 6 & 25
\end{tabular}

No. of metastatic lesions

\begin{tabular}{|l|c|c|}
\hline 1 & 9 & 37 \\
2 & 4 & 17 \\
3 & 7 & 29 \\
4 & 4 & 17 \\
\hline Site of metastatic disease & 21 & 88 \\
\hline Bone & 9 & 38 \\
Lung & 5 & 21 \\
Liver & 24 & 100 \\
\hline Previous endocrine therapy & 23 & 96 \\
\hline Adjuvant setting & 18 & 82 \\
Metastatic setting & & \\
\hline
\end{tabular}

No. of prior lines of endocrine therapies for metastatic disease

\begin{tabular}{|c|c|c|}
\hline 1 & 15 & 65 \\
\hline 2 & 5 & 22 \\
\hline 3 & 2 & 9 \\
\hline 4 & 1 & 4 \\
\hline $\begin{array}{l}\text { No. of patients previously treated with } \\
\text { chemotherapy for metastatic disease }\end{array}$ & 5 & 26 \\
\hline \multicolumn{3}{|l|}{ CT regimens prior to enrolment } \\
\hline CMF & 2 & 9 \\
\hline Taxane & 1 & 4 \\
\hline AC-taxane & 1 & 4 \\
\hline Vinorelbine & 1 & 4 \\
\hline Prior radiation therapy for metastatic disease & 11 & 46 \\
\hline Bone & 9 & 38 \\
\hline Lymph nodes & 1 & 4 \\
\hline Breast & 1 & 4 \\
\hline \multicolumn{3}{|c|}{$\begin{array}{l}\text { Abbreviations: } \mathrm{AC}=\text { doxorubicin plus cyclophosphamide; } \mathrm{CMF}=\text { cyclophosphamide } \\
\text { methotrexate and } 5 \text {-fluorouracil; } \mathrm{CT}=\text { chemotherapy; } \mathrm{ECOG}=\text { Eastern Cooperative } \\
\text { Oncology Group. }\end{array}$} \\
\hline
\end{tabular}


Table 3. Details of endocrine therapies prior to study enrolment

\begin{tabular}{|l|c|c|c|c|}
\hline $\mathbf{n}(\%, \mathbf{n}=\mathbf{2 4 )}$ & $\begin{array}{c}\text { First } \\
\text { hormonal } \\
\text { regimen }\end{array}$ & $\begin{array}{c}\text { Second } \\
\text { hormonal } \\
\text { regimen }\end{array}$ & $\begin{array}{c}\text { Third } \\
\text { hormonal } \\
\text { regimen }\end{array}$ & $\begin{array}{c}\text { Fourth } \\
\text { hormonal } \\
\text { regimen }\end{array}$ \\
\hline $1(4.2)$ & None & None & None & None \\
\hline $8(33.3)$ & $\mathrm{Al}$ & None & None & None \\
\hline $3(12.5)$ & $\mathrm{Al}$ & $\mathrm{Al}$ & None & None \\
\hline $1(4.2)$ & $\mathrm{Al}$ & Other & None & None \\
\hline $1(4.2)$ & Tamoxifen & Al & None & None \\
\hline $2(8.3)$ & Tamoxifen & Al & Unknown & None \\
\hline $1(4.2)$ & Tamoxifen & Megestrol & Unknown & Unknown \\
\hline $\begin{array}{l}\text { Abbreviation: Al }=\text { aromatase inhibitor. } \\
\text { a Other: not specified, but not tamoxifen, Al, ovarian suppression/ablation or megestrol. }\end{array}$
\end{tabular}

Protocol 06-091 progression-free survival from enrolment

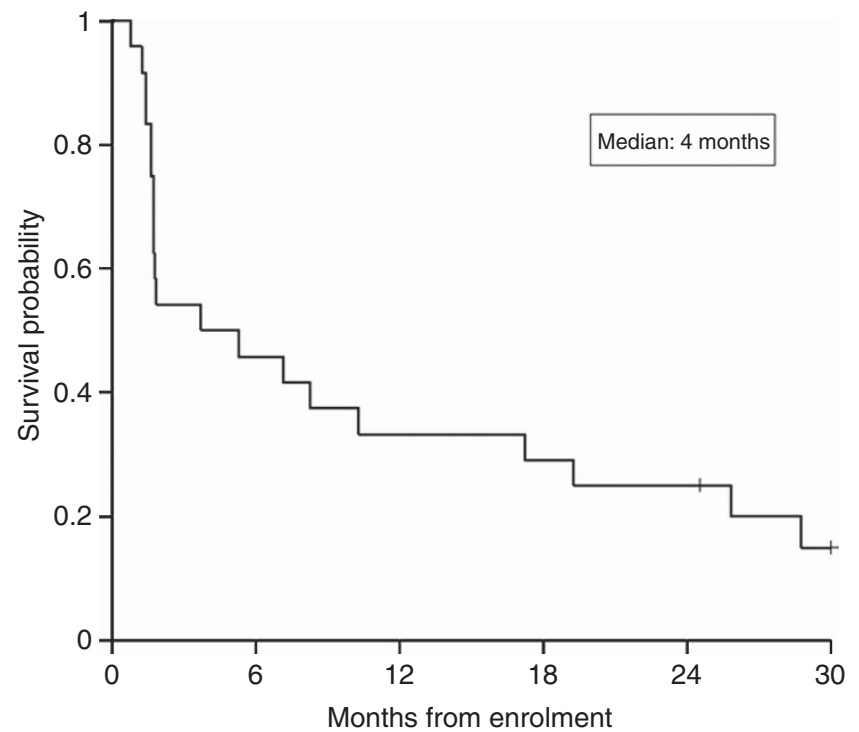

Figure 2. The median progression-free survival of all patients was 4 months ( $95 \% \mathrm{Cl} 2$ months to 17 months).

doses of oestrogens have been given to patients with such disease progression (Ingle, 2002; Ellis et al, 2009).

Therefore, in the clinical setting, the withdrawal of the AI at the time of tumour progression while on treatment could result in resensitivity to oestrogen, albeit to just normal menopausal levels. Thus moving immediately from one endocrine therapy to another in hormone-receptor-positive MBC, may be the wrong strategy in some patients.

We are aware that this is a small phase 2 study, however, our results are strongly suggestive of a withdrawal response in some patients: half of the patients with MBC progressing on AI therapy experienced disease stabilisation after withdrawal of the AI therapy. Two patients had remained progression free after 60 months (in one patient PFS was 73 months and had three sites of metastatic disease (bone, lymph nodes and contralateral breast). The other patient PFS was 66 months and had only one site of bone metastasis. Both patients had and ECOG of 0 and none of them received prior metastatic chemotherapy regimens). The PFS observed in our trial was of 4 months, which compares favourably to the PFS achieved with alternative options such as exemestane or fulvestrant, with a median PFS duration from 4 to 7 months, respectively, for patients with hormone-receptor-positive breast
Protocol 06-091 overall survival from enrolment

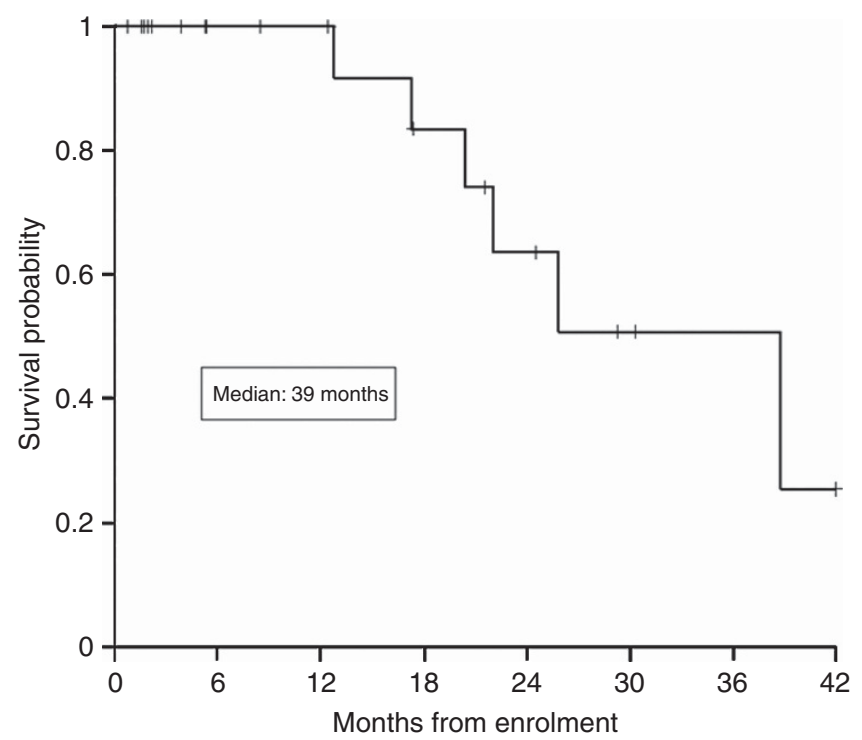

Figure 3. The median overall survival of all patients was 39 months.

cancer (Chia et al, 2008; Di Leo, et al, 2011). We acknowledge a number of limitations of our study: it is a single-arm trial with a high likelihood of selection bias in favour of patients with more favourable tumour biology. With this caveat in mind unlike in the tamoxifen withdrawal trial published by Howell et al, we saw no objective disease remissions. Other possible selection biases include the following: patients were excluded from trial entry if their treating physician felt that they needed palliative chemotherapy, which potentially limited the study population to patients with slow-growing disease; the median age of our patients was 63 and many had bone-only disease (29\%).

To our knowledge, this is the first and only prospective study of AI therapy withdrawal, which needs to be further, explored in a randomised trial. If the trend of our trial is confirmed this strategy could lead to a well tolerated, inexpensive and effective therapeutic option for selected patients with slowly progressing disease on endocrine therapy.

\section{ACKNOWLEDGEMENTS}

We are grateful to the women who agreed to participate in this study. This study was supported and funded by the Avon Foundation, New York. This funding source had no role in the planning or writing of this manuscript.

\section{CONFLICT OF INTEREST}

PEG has received speakers honoraria from GSK, Novartis and Pfizer. The remaining authors declare no conflict of interest.

\section{AUTHOR CONTRIBUTIONS}

YC-G, MJH and PL contributed to data analysis and interpretation, manuscript writing and final approval of the manuscript. JS was involved in collection and assembly of data, data analysis and interpretation, manuscript writing and final approval of the manuscript. TC contributed to conception and design, data analysis and interpretation, manuscript writing, and final approval 
of the manuscript. AP, JL and SEC contributed to data analysis and interpretation, manuscript writing, final approval of the manuscript and provision of study materials or patients. DF was involved in conception and design, collection and assembly of data, data analysis and interpretation, manuscript writing and final approval of the manuscript. PDR contributed to conception and design, data analysis and interpretation, manuscript writing, final approval of the manuscript and provision of study materials or patients. PEG was responsible for conception and design, collection and assembly of data, data analysis and interpretation, manuscript writing, final approval of the manuscript, financial support, administrative support and provision of study materials or patients.

\section{REFERENCES}

Agrawal A, Robertson JFR, Cheung KL (2011) Clinical relevance of "withdrawal therapy" as a form of hormonal manipulation for breast cancer. World J Surg Oncol 9: 101.

Belani CP, Pearl P, Whitley NO, Aisner J (1989) Tamoxifen withdrawal response: report of a case. Arch Intern Med 149: 449-450.

Bhide SA, Rea DW (2004) Metastatic breast cancer response after exemestane withdrawal: a case report. Breast 13: 66-68.

Bonneterre J, Thürlimann B, Robertson JF, Krzakowski M, Mauriac L, Koralewski P, Vergote I, Webster A, Steinberg M, von Euler M (2000) Anastrozole versus tamoxifen as first-line therapy for advanced breast cancer in 668 postmenopausal women: results of the tamoxifen or arimidex randomized group efficacy and tolerability study. J Clin Oncol 18: $3748-3757$

Buzdar AU, Robertson JF, Eiermann W, Nabholtz JM (2002) An overview of the pharmacology and pharmacokinetics of the newer generation aromatase inhibitors anastrozole, letrozole, and exemestane. Cancer 95: 2006-2016.

Chia S, Gradishar W, Mauriac L, Bines J, Amant F, Federico M, Fein L, Romieu G, Buzdar A, Robertson JF, Brufsky A, Possinger K, Rennie P, Sapunar F, Lowe E, Piccart M (2008) Double-blind, randomized placebo controlled trial of fulvestrant compared with exemestane after prior nonsteroidal aromatase inhibitor therapy in postmenopausal women with hormone receptor-positive, advance breast cancer: results from EFFECT. J Clin Oncol 26: 1664-1670.

Cigler T, Goss PE (2006) Aromatase inhibitor withdrawal response in metastatic breast cancer. J Clin Oncol 24: 1955-1956.

Di Leo A, Jerusalem G, Petruzelka L, Torres R, Bondarenko IN, Khasanov R, Verhoeven D, Pedrini JL, Smirnova I, Lichinitser MR, Pendergrass K, Garnett S, Lindemann JP, Sapunar F, Martin M (2011) Results of the CONFIRM phase III trial comparing fulvestrant $250 \mathrm{mg}$ with fulvestrant $500 \mathrm{mg}$ in postmenopausal women with estrogen receptor-positive advanced breast cancer. J Clin Oncol 28: 4594-46002010. (Erratum, J Clin Oncol 29:2293).

Ellis MJ, Gao F, Dehdashti F, Jeffe DB, Marcom PK, Carey LA, Dickler MN, Silverman P, Fleming GF, Kommareddy A, Jamalabadi-Majidi S, Crowder R, Siegel BA (2009) Lower-dose vs high-dose oral estradiol therapy of hormone receptor-positive, aromatase inhibitor-resistant advanced breast cancer: a phase 2 randomized study. JAMA 302: $774-780$.

Guerrieri-Gonzaga A, Baglietto L, Johansson H, Bonanni B, Robertson C, Sandri MT, Canigiula L, Lampreda C, Diani S, Lien EA, Decensi A (2001) Correlation between tamoxifen elimination and biomarker recovery in a primary prevention trial. Cancer Epidemiol Biomarkers Prev 10: 967-970.
Howell A, Dodwell DJ, Anderson H, Redford J (1992) Response after withdrawal of tamoxifen and progestogens in advanced breast cancer. Ann Oncol 3: 611-617.

Ingle JN (2002) Estrogen as therapy for breast cancer. Breast Cancer Res 4: $133-136$.

Johnston SRD (2010) New strategies in estrogen receptor-positive breast cancer. Clin Cancer Res 16: 1979-1987.

Lambertini M, Pronzato P, Giraudi S, Levaggi A, Bighin C, Del Mastro L (2011) Letrozole withdrawal response in locally advanced breast cancer. Ann Oncol 22: 1927-1928.

Legault-Poisson S, Jolivet J, Poisson R, Beretta-Piccoli M, Band PR (1979) Tamoxifen-induced tumor stimulation and withdrawal response. Cancer Treat Rep 63: 1839-1841.

Masamura S, Santner SJ, Heitjan DF, Santen RJ (1995) Estrogen deprivation causes estradiol hypersensitivity in human breast cancer cells. J Clin Endocrinol Metab 2918-2925.

Milla-Santos A, Milla L, Portella J, Rallo L, Pons M, Rodes E, Casanovas J, Puig-Gali M (2003) Anastrozole versus tamoxifen as first-line therapy in postmenopausal patients with hormone-dependent advanced breast cancer-a prospective, randomized, phase III study. Am J Clin Oncol 26: $317-322$.

Mouridsen H, Gershanovich M, Sun Y, Pérez-Carrión R, Boni C, Monnier A, Apffelstaedt J, Smith R, Sleeboom HP, Jänicke F, Pluzanska A, Dank M, Becquart D, Bapsy PP, Salminen E, Snyder R, Lassus M, Verbeek JA, Staffler B, Chaudri-Ross HA, Dugan M (2001) Superior efficacy of letrozole versus tamoxifen as first-line therapy for postmenopausal women with advanced breast cancer: results of a phase III study of the International Letrozole Breast Cancer Group. J Clin Oncol 19: 2596-2606.

Nabholtz JM, Buzdar A, Pollak M, Harwin W, Burton G, Mangalik A, Steinberg M, Webster A, von Euler M (2000) Anastrozole is superior to tamoxifen as first-line therapy for advanced breast cancer in postmenopausal women: results of a North American multicenter randomized trial. J Clin Oncol 18: 3758-3767.

Osipo C, Gajdos C, Cheng D, Jordan VC (2005) Reversal of tamoxifen resistant breast cancer by low dose estrogen therapy. J Steroid Biochem Mol Biol 93: 249-256.

Paridaens RJ, Dirix LY, Beex LV, Nooij M, Cameron DA, Cufer T, Piccart MJ, Bogaerts J, Therasse P (2008) Phase III study comparing exemestane with tamoxifen as first-line hormonal treatment of metastatic breast cancer in postmenopausal women: the European Organisation for Research and Treatment of Cancer Breast Cancer Cooperative Group. J Clin Oncol 26 : 4883-4890.

Shim WS, Conaway M, Masamura S, Yue W, Wang JP, Kmar R, Santen RJ (2000) Estradiol hypersensitivity and mitogen-activated protein kinase expression in long-term estrogen deprived human breast cancer cells in vivo. Endocrinology 141: 396-405.

Song RX, Mor G, Naftolin F, McPherson RA, Song J, Zhang Z, Yue W, Wang J, Santen RJ (2001) Effect of long-term estrogen deprivation on apoptotic response of breast cancer cells to 17beta-estradiol. J Natl Cancer Inst 93: 1714-1723.

Therasse P, Arbuck SG, Eisenhauer EA, Wanders J, Kaplan RS, Rubinstein L, Verweij J, Van Glabbeke M, van Oosterom AT, Christian MC, Gwyther SG (2000) New guidelines to evaluate the response to treatment in solid tumors. European Organization for Research and Treatment of Cancer, National Cancer Institute of the United States, National Cancer Institute of Canada. J Natl Cancer Inst 92: 205-216.

This work is published under the standard license to publish agreement. After 12 months the work will become freely available and the license terms will switch to a Creative Commons AttributionNonCommercial-Share Alike 3.0 Unported License. 